\title{
The benefits of integrating European electricity markets
}

\author{
David Newbery, ${ }^{\mathrm{a}, \mathrm{b}, 1}$ Goran Strbac, ${ }^{\mathrm{b}}$ Ivan Viehoff ${ }^{\mathrm{c}}$ \\ ${ }^{a}$ Energy Policy Research Group, University of Cambridge, Cambridge CB3 9DE, UK \\ ${ }^{\mathrm{b}}$ Control and Power Research Group, Imperial College London, London SW7 2AZ, UK \\ ${ }^{\mathrm{c}}$ CEPA, London WC2A 3LJ, UK
}

9 September 2015

Revised 12 February 2016

\begin{abstract}
The European Commission's Target Electricity Model (TEM) aims to integrate EU electricity markets. This paper estimates the potential benefit of coupling interconnectors to increase the efficiency of trading day-ahead, intra-day and balancing services across borders. Further gains are possible by eliminating unscheduled flows and avoiding the curtailment of renewables with better market design. In the short run the gains could be as high as $€ 3.9$ billion/yr, more than $100 \%$ of the current gains from trade. About onequarter of this total comes from day-ahead coupling and another third from shared balancing. If shared balancing is so valuable, completing the TEM becomes more urgent, and regulators should ensure these gains are paid to interconnectors to make the needed investment in the cross-border links more commercially profitable.
\end{abstract}

Keywords: electricity market coupling, interconnectors, balancing, benefits

Classification codes: D61, F15, L51, L94

\footnotetext{
${ }^{1}$ Correspondence to: Faculty of Economics, University of Cambridge, Sidgwick Avenue,

Cambridge CB3 9DE, UK, Tel: +44 1223335248

E-mail address: dmgn@,cam.ac.uk
} 


\section{Introduction}

The European Union is, by the end of 2015, part way through the process of further integrating EU electricity markets by rolling out the Target Electricity Model (TEM). Most Member States have effectively implemented the TEM at the day-ahead stage, and by the end of 2014 the share of market coupling had risen from $60 \%$ in 2010 to $86 \%$ (ACER, 2015, p15). The harder intra-day allocation and shared balancing is still work in progress and not expected before the end of 2017. A key part of the TEM is improving the efficiency of cross-border trade over interconnectors. If that leads to a material increase in benefits, then two policy implications follow. First, these gains need to be reflected in payments to the infrastructure providing these services. In some cases, notably cross-border balancing, this does not yet happen. Second, if payments to interconnectors are materially increased, the commercial profitability of, and hence pressure to build, more interconnection will also increase and help meet the European Commission's ambitious targets for cross-border links.

The materiality of the gains from integration is also important as the required market reforms are costly in terms of changing software and market operations, and certainly run into tens of millions of euros for each Member State. As an example, when Britain replaced the centrally dispatched Electricity Pool by an energy-only market (NETA) in 2001, the UK's National Audit Office estimated "that market participants could incur total costs of up to $£ 580$ million in implementing NETA over the first 5 years, and then operating costs of $£ 30$ million a year." (NAO, 2003).

It is therefore timely to measure the benefits of market integration to judge whether the enterprise is worthwhile, whether it is so beneficial that it should be 
completed more rapidly despite the difficulties, and whether it materially affects the profitability of investment in interconnectors. If, as argued here, the benefits are indeed large - several billions of euros per annum - then it becomes more urgent to accelerate the last difficult parts of the TEM, particularly sharing balancing services and reserves across borders and ensuring that potential interconnector investors see these gains reflected in profits and press for more and faster interconnections.

The TEM is part of the wider Third Internal Energy Market Package that came into force in 2011 with among other objectives “... to urgently upgrade Europe's networks, interconnecting them at the continental level, in particular to integrate renewable energy sources. ${ }^{2}$ To press for continued and faster market integration DG ENER commissioned the authors to estimate the benefits of integrating electricity (and gas) markets (Newbery, et al, 2013).

This paper sets out the methods used in that report and extends the results, using additional data published by $\operatorname{ACER}(2014,2015)$ that was collected in response to our report. This paper adds to ACER's estimates by extrapolating ACER's partial coverage to the EU-28, using later data where this corrects earlier estimates (e.g. for unscheduled flows), but attempting to measure the pre-coupling situation. Although these are necessarily somewhat speculative, they identify more clearly the sources of major potential integration gains, although they do not include additional gains from the resulting increased competition. Where appropriate we compare our estimates with ACER's estimates, but while ACER's annual market reports are directed at monitoring

\footnotetext{
${ }^{2}$ http://eur-lex.europa.eu/legalcontent/EN/TXT/?qid=1441631107710\&uri=URISERV:180202_1
} 
progress across a wide range of topics (such as retail competition and the gas markets) our aim here is to step back and assess the integration benefits of the TEM as it applies to wholesale electricity markets.

Electricity market integration under the TEM couples cross-border interconnectors so that all electricity is (moderately) efficiently allocated across the EU by a single auction platform, Euphemia (Pan-European Hybrid Electricity Market Integration Algorithm). ${ }^{3}$ By mid-2014 the day-ahead coupling objective had been achieved from Finland to Portugal, including Great Britain. Coupling means that wholesale electricity prices should be equalized across boundaries unless the interconnector is constrained, in which case prices can diverge but the interconnector should be fully utilized. Before market coupling, capacity on interconnectors was sold before the day-ahead markets opened, and traders had to predict the price differences across interconnectors and bid for that capacity. Traders faced the risk that on the day the trade would no longer be profitable, in which case the option to flow power would be abandoned and the interconnector would be under-used, or, worse, the power would flow from the high price to the low price zone.

The EU electricity market has an installed capacity of $948 \mathrm{GW}$ in 2012, an annual production of 3,010 TWh in 2014 and trade between Member States in 2011 of 315 $\mathrm{TWh} / \mathrm{yr}$, about the EU target of $10 \%$ traded power. If its average value is $€ 50 / \mathrm{MWh}$, production would be worth about $€ 150$ billion/yr. If the average value of capacity is

\footnotetext{
${ }^{3}$ See PCR (2016) for a description of the algorithm and its workings
} 
$€ 500 / \mathrm{kW},{ }^{4}$ the installed capacity would be valued at some $€ 500$ billion. As part of the argument for closer integration, "the Commission estimated that about $€ 200$ billion of investment would be needed by 2020 in energy infrastructure Europe-wide."5 Given these large sums, a small improvement in efficiency could amount to a large absolute sum of money.

The next section summarizes existing estimates of the benefits of market integration. Section 3 sets out the methods for their estimation, section 4 presents the data calculates the arbitrage gains from market coupling, section 5 gives estimates if the other benefits of integration, and section 6 concludes.

\section{Estimating the benefits of market integration}

The two main methods of computing the potential benefits of market integration are to build a simulation model of the relevant area (ideally, the whole EU, normally some region) and compare the results with and without market coupling, as in some of the studies listed below and one used in this paper (Pudjianto et al. 2014), or to examine individual interconnectors before and after reforms. The first runs into the problem that it is challenging to replicate flows and generation even with a greatly simplified

\footnotetext{
${ }^{4}$ The cost of a new Combined Cycle Gas Turbine is about $€ 1,000 / \mathrm{kW}$. New coal-fired stations cost around $€ 1,800 / \mathrm{kW}$, about the same as on-shore wind. Nuclear power and off-shore wind are more than twice these amounts. While existing stations are old and largely written down, their lower-carbon replacements are likely to be more costly than the $€ 1,000 / \mathrm{kW}$, partly because more capacity will be needed to deliver reliability.

${ }^{5}$ http://www.europarl.europa.eu/atyourservice/en/displayFtu.html?ftuId=FTU 5.7.2.html
} 
representation, particularly in the presence of market power (Neuhoff et al. 2005). The second runs into the usual problems that other factors (e.g. fuel prices) also change over the period studied and general equilibrium/network effects are ignored. The first of these objections is partially allayed as these factors will likely affect prices at both ends of the interconnector, and the benefits depend on differences across the borders. The second is more serious in meshed networks and much less of a problem with links to isolated systems (e.g. to GB, Spain), but still has to be addressed by estimating possible price impacts.

Most of the following studies use the simulation approach, where estimating the benefits of more efficient electricity market integration has attracted intermittent attention in different jurisdictions and for a variety of reasons. ${ }^{6}$ Neuhoff et al. (2011) explored the benefits of the most efficient form of market integration via nodal pricing (as in $\mathrm{PJM}^{7}$ ) but including a large volume $(125 \mathrm{GW})$ of predicted future wind connection. They found savings of $1.1-3.6 \%$ of variable operating costs. If variable (mainly fuel) costs are roughly half total wholesale market value then the gains from full integration would be 0.6-1.8\% of wholesale market value. Leuthold et al (2005) simulated the benefits of adding $8 \mathrm{GW}$ of offshore wind to Germany and moving to nodal pricing, estimating that gains of $0.6-1.3 \%$ came just from a move to nodal pricing and an additional $1 \%$ would come from nodally pricing the additional wind.

\footnotetext{
${ }^{6}$ A fuller literature review is provided in Newbery et al. (2013).

${ }^{7}$ Originally the Pennsylvania-New Jersey-Maryland interconnection, since expanded considerably.
} 
One important study comparing before and after over a wide region is that of Mansur and White (2009), although their study is the more ambitious one of comparing different market designs, not just the benefits of market integration, but moving from bilateral trading to simultaneous market dispatch and clearing. They compared monthly prices before and after a bilaterally cleared zone joined PJM's nodally priced market area to estimate reductions in price spreads, and estimated welfare gains in the same way that this paper does. They found incremental gains of $\$ 3.6$ million/GW capacity, which if applied to the EU with $950 \mathrm{GW}$ capacity would deliver $\$ 3.4(€ 2.6)$ billion/yr or $1.7 \%$ of wholesale value. Ott (2010), building on Mansur and White's (2009) study, found that the total benefits of efficiently pricing PJM were $\$ 2.2 \mathrm{bn} / \mathrm{yr}$. However, these estimates are the benefits of moving to nodal pricing, whereas the TEM stops short at zonal pricing and so would not realize the full potential gains. PJM as a centrally dispatched system also automatically integrates intra-day and balancing, but these benefits existed before nodal pricing.

When it comes to estimating the benefits of market coupling the literature is even sparser. De Jong, Hakvoort and Sharma (2007) simulated a simplified model of France, Germany, The Netherlands and Belgium ( $42 \%$ of total EU-28 production). They estimated the welfare effects of flow-based market coupling (FBMC) at about $€ 200 \mathrm{~m} / \mathrm{yr}$. ${ }^{8}$ Meeus (2011) studied the history of the 600 MW Kontek HVDC cable from East Denmark to Germany, first from the period of no coupling, through two implementations

\footnotetext{
${ }^{8}$ ACER (2015, p156) compares FBMC with the existing transitional approach using Available Transfer Capacity (ATC) and finds gains in flows where FBMC has been implemented (since May 2015) of up to $60 \%$ but more typically of $10 \%$.
} 
of approximate coupling, ending with one-way market coupling, still imperfect as it resulted in flows against the price differential (FAPD) of about $5 \%$. The estimated welfare gain was about $€ 10 \mathrm{~m}$ per year on that one cable or about $€ 17$ million/GWyr, much higher than the PJM estimates.

SEM Committee (2011) estimated the social costs of not coupling the two interconnectors between GB and the Single Electricity Market (SEM) of the island of Ireland (which had a combined capacity of 950/910MW imports depending on the season but only 580MW exports) for 2010. The estimates included price responses and a dead band (with no trade) of $€ 5 / \mathrm{MWh}$ to allow for various losses and transmission access charges. The social welfare gains from coupling were estimated at $€ 30$ million per year for an average import capacity of $930 \mathrm{MW},{ }^{9}$ or $€ 32$ million/GWyr, more than twice that of the Kontek cable.

In summary, simulation studies of FBMC find modest efficiency benefits that may underestimate the potential for two reasons. The models lack sufficient richness to identify all of the transmission difficulties that FBMC may relieve, and they are calibrated to earlier generation portfolios with less renewable generation and therefore likely less transmission congestion than now. They indicate substantial value to increasing transmission capacity, and that FBMC will then be of even greater value in efficiently managing that capacity.

Since our report several new studies have been published, as well as the ACER annual reports discussed below. Böckers et al (2013) measure the extent to which market integration can share peak demand more efficiently, and find that about half of

\footnotetext{
${ }^{9}$ The export capacity is lower but exports are much less common.
} 
neighboring countries' peak demands is non-coincident and so the capacity needed to supply them jointly could be reduced. They report studies of price convergence that shows in some pair-wise comparisons that considerable convergence preceded coupling. They also report earlier studies that simulate the gains from improved competition and hence lower deadweight losses that our report did not explore. They roughly estimated gains from harmonizing PV support schemes and found large benefits (more than $€ 700$ million/yr just by reallocating support from Germany to Spain). Newbery et al. (2013) looked forward to 2030 and found very large gains from harmonizing all renewables support, but these potential gains are not discussed in this paper. National Grid (2015) found that sharing reserves over interconnectors might reduce capacity needs by $2.8 \mathrm{GW}$, which at the 2014 capacity auction price of $£ 19.40 / \mathrm{kWyr}$ would be worth $€ 15$ million/GWyr, comparable to the Kontek cable.

Pellini's (2014) doctoral dissertation used a power simulation model of Italy with econometric estimates of price formation in bordering markets to examine the benefits of coupling the Italian market for 2012. She found that in the reference scenario for 2012 and allowing for continued market power, market coupling increased net welfare (the arithmetic sum of changes in producer, consumer and transmission surpluses) by $€ 33$ million/yr (M€/yr), but if coupling credibly increased competition on the northern border, the net welfare gain rose to $396 \mathrm{M} € / \mathrm{yr}$, although this is still $278 \mathrm{M} € / \mathrm{yr}$ below that theoretically achievable under perfect competition. In the high scenario in which the economy recovered relative to 2010 and oil prices were higher, the welfare gain from coupling increased to $132 \mathrm{M} € / \mathrm{yr}$ without more competition, and to $742 \mathrm{M} € / \mathrm{yr}$ with more competition, $326 \mathrm{M} € / \mathrm{yr}$ short of perfect competition. These simulation results show that 
the gains from integration can be highly sensitive to relative fuel prices (which clearly can affect the gains from trade), the level of demand in the importing country (Italy) particularly in the presence of market power and hence rapidly rising prices as demand tightens, and of course the impact that coupling has on market power.

\section{Method of Analysis}

Estimating the benefits of integration is not straightforward, as it inevitably involves either comparing the status quo ex ante with a counterfactual, or comparing the situations before and after, in which many other factors may have changed, including the whole pattern of generation and cross-border flows and with that the pattern of price differences across interconnectors. As noted above, the first method requires simulation models. The most sophisticated of these are large commercial software models (PowerSym, Plexos, etc.) that require massive data (much of it unavailable even to ACER or ENTSO-E). They typically compute efficient dispatch and thus ignore issues of market power. Tractable models inevitably simplify the grid representation, generation costs, market power and modeling flows before and after integration. The second method, adopted here, has other problems listed above. Our approach improves upon the simple ACER methodology by estimating possible price changes caused by flows over the interconnector under study, but if all interconnectors are coupled, then flows will increase more widely and should lead to additional price convergence. This will have the effect of shifting the ex post supply and demand schedules on each interconnector to the left, amplifying price convergence that will further reduce the estimated social welfare gain on each interconnector, only part of which is captured by our modeled price changes. Our over- 
estimate should not be exaggerated, as interconnector flows at full capacity are still modest compared to total generation.

Other unrecorded impacts likely go in the other direction. As well as the directly observable impacts of increased flows and price changes as interconnectors are more efficiently used, there are harder to identify indirect benefits that may flow from increased cross-border competition, such as pressures to reduce cost, innovate, improve market functioning through increased liquidity, and improved sustainability if the volume of low-carbon electricity that can be delivered to final consumers increases and displaces more polluting sources. Improved market monitoring of the kind conducted by ACER also identifies other sources of potential improvement, such as moving from ATC to FBMC methods of calculating interconnection capacity, and comparing thermal and ATC limits (e.g. ACER, 2015, §4.3.1.2). This last is a measure of the potential benefits of moving to nodal pricing and will be discussed below under unscheduled flows in $§ 4.5$. Security of supply should improve, although the full benefits of reducing EU-wide reserve capacity needed requires those responsible for assuring security to make changes in the way they assess system security and adjust domestic capacity. ${ }^{10}$

\footnotetext{
${ }^{10}$ Thus in the preparations for the UK 2014 capacity auction designed to deliver the specified security standard of a Loss of Load Expectation of 3 hours per year, the minister responsible, on the advice of the Transmission System Operator, set a standard that ignored any net contribution that the interconnectors might supply - see DECC (2014), National Grid (2014) and Newbery and Grubb (2015). Under pressure from DG COMP interconnector flows are now included in capacity adequacy assessments, but region-wide security studies are still imperfect.
} 
In the longer run, the economics of building interconnectors should improve, encouraging further investment and allowing a more efficient location of generation across the EU to exploit the gains from improved trade. This is particularly the case with efficiently locating renewables where the resource (sun or wind) is best suited, and that will require more efficient forms of EU-wide support finance and burden sharing (Newbery, 2016).

\subsection{Measuring arbitrage gains from coupling}

The methodology for estimating the gains from coupling interconnectors at the day-ahead stage (largely complete by the end of 2014) is standard (c.f. Mansur and White, 2009) and measures the change in consumer and producer surplus, ${ }^{11}$ as shown in Figure 1.

\section{Fig. 1}

Figure 1a shows one possible configuration of the interconnector before and after coupling. Volume A is the amount used before coupling with the net supply schedule in the direction of trade, EG, and the net demand schedule, DH, shown. Market coupling then leads to the full utilization of the interconnector to volume B, narrowing the price difference as shown. The benefit of coupling is then the darker colored trapezium, on the (competitive market) assumption that the net supply represents the marginal cost (including any scarcity rents) and the net demand represents the willingness to pay for

\footnotetext{
${ }^{11}$ This assumes that the prices in each market are equal to system marginal cost, SMC, or are competitive and that the supply and demand schedules do not change (as noted above, general equilibrium effects can shift both schedules to the left). If prices are above SMC, there is an additional gain equal to the change in trade times the mark-up between price and SMC, so this measure is conservative.
} 
power. In algebraic terms the benefit is the average of the price differences before and after coupling times the increase in the volume of trade or the area of the trapezium DEGH. If coupling eliminated the price difference, as it does in Figure $1 \mathrm{~b}$, the benefit of coupling is only one half the rectangle assuming no price change.

Figure $1 \mathrm{~b}$ shows the case in which the interconnector is flowing power in the wrong direction. In this case point A corresponds to, say, importing a volume $0 \mathrm{~A}$ when the efficient coupled solution would be exporting an amount $0 \mathrm{C}$ (the capacity of the interconnector is $0 \mathrm{~B}$ in each direction, although there is no reason why export and import capacity should be the same). In this case the benefit is half the initial price difference ED times the volume $\mathrm{AC}$, or the area $\mathrm{DEH}$, which is half the area DEGF that assumes prices do not change.

ACER (2013) makes the simplifying assumption that the prices do not change, which can be justified as it is very difficult to estimate the various price changes that would arise in the Continental meshed AC network. It is easier to do this for DC links that connect two separate markets with different prices. Ignoring price changes would tend to over-estimate the gains by measuring the area DEFK in figure 1a if the estimate is made before coupling, but underestimate the gains if the post-coupled price difference is used. Newbery et al (2013) estimated that in the case of the England-France interconnector (IFA), a change of trade of $1 \mathrm{GW}$ into Britain would change British wholesale prices by $€ 1 / \mathrm{MWh}$. Larger price zones such as GB will tend to have smaller price impacts, and as GB is one of the larger EU price zones, ${ }^{12}$ this rough estimate might

\footnotetext{
${ }^{12}$ There are 50 bidding areas covered by Euphemia but France and Germany are the only single price zones larger than GB.
} 
tend to underestimate the gains from Continental coupling. In figure 1a this requires correcting the measured loss DEFK by subtracting the areas DKH and EFG, where the sum of $\mathrm{KH}$ and $\mathrm{GF}$ is given by the slope $€ 1 / \mathrm{MWh} / \mathrm{GW}$ and the change $\mathrm{AB}$. This is half times the change in volume times the change in price, or equivalently $1 / 2 \times 1 \times \mathrm{AB}^{2}$.

\subsection{Example: the France-England interconnector}

In 2011 exports from $\mathrm{FR} \rightarrow \mathrm{UK}$ used $58 \%$ of total capacity and from $\mathrm{UK} \rightarrow \mathrm{FR}$ a further $12 \%$, making the overall utilization of IFA $71 \%$. (As an example of the approach see appendix table A1.) The average Net Transfer Capacity (NTC) in both 2011 and 2012 was roughly $1.25 \mathrm{GW}$ in each direction so an under-utilization of $29 \%$ is $0.36 \mathrm{GW}$. The estimated price change is $€ 0.36 / \mathrm{MWh}$, and the adjustment is half this or $€ 0.18 / \mathrm{MWh}$. The underutilization was $14 \mathrm{TWh}$; so the overstatement is $€ 2.5$ million, reducing the total 2011 loss estimate, ignoring price changes, of $€ 22.4$ million to $€ 20$ million, or by $10 \%$ (so not insignificant). In 2012 the underutilization was 12.7 TWh so the overstatement was $€ 2.3$ million, reducing the total 2012 loss from $€ 20.8$ million to $€ 18.5$ million or by $12 \%$ (Newbery et al, 2013, tables $8.2,8.4$ ). The error in ignoring price impacts increases as the square of the shortfall, and so becomes smaller as interconnectors are more fully used. At the other extreme, if coupling eliminates the price difference, then the actual gain would be only half the measured gain assuming no price change.

\section{Data and estimates}

The results of comparing the original estimates in Newbery et al. (2013) with the more comprehensive ACER $(2014,2015)$ estimates are illuminating and are summarized in 
aggregate in Table 3 below. The estimates in Newbery et al. (2013) concentrated on a few interconnectors (accounting for about $6 \mathrm{GW}$ NTC) for which there was good data and which were not then coupled, and then developed other estimates for the future from market modeling while ACER had access to a wider (but still not comprehensive) set of interconnector data and more details about other services. The most recent ACER (2015) report normally aggregates over $46-48$ border crossings, and reports that NTC averages for the regions studied remained roughly constant in aggregate (but not in all regions) from 2010-2014 at $50 \mathrm{GW}$. Trade of day-ahead nominations across a selection of interconnectors increased by $18 \%$ from $2011-14$, presumably in response to coupling (ACER, 2015, fig 62). This paper uses the ACER data but extrapolates to provide EUwide estimates of the benefits of coupling by relating gains to interconnector capacities. The following sections quantify the gains by interconnector and per GW NTC for the different sources of benefits.

\subsection{Estimating day-ahead arbitrage gains from market coupling}

The social welfare losses on England-France interconnector IFA adjusted for price changes and resistive losses of $2 \%$ were $22 \%$ of the total potential arbitrage value of trade in 2011 (30\% of actual value) and 12\% of a higher potential value in $2012(14 \%$ of actual value), averaging $16 \%$ of potential value ( $20 \%$ of actual value). ${ }^{13}$

The Germany-France interconnection became coupled in Q4 2010 so the loss on the German-France interconnection was estimated for Q1-Q3 2010. The estimated loss was $26 \%$ of potential value, ignoring resistive losses because these interconnectors are short AC links connecting nodes adjacent to borders. The losses for France-Spain 2011

${ }^{13}$ Newbery et al (2013) tables 8.2 and 8.4 , corrected for the price change. 
and 2013 (not given in our report but given in Appendix Table A1) were 11\% and 12\%, again ignoring resistive losses.

In conclusion, Newbery et al. (2013) estimated the social losses of not coupling day-ahead for these examples at $10-20 \%$ of arbitrage value, depending on the year, the interconnector, and market prices. After coupling, these losses should fall to zero. To put this into context, EU exports (and imports) in 2011 were about $315 \mathrm{TWh}$ out of 3,080 TWh supplied in that year (or about $10 \%$ ).

These welfare losses on the interconnectors were estimated as a percentage of the gains from trade, which is the arbitrage gain from the price difference, not the standard measure of the value of trade, which is the price of the product times the volume traded. Thus to scale up the evidence from a few interconnectors one needs this measure of the gains from total EU-29 trade, which is difficult to estimate as it depends on price differences across the borders. One way to derive a very rough estimate is to note that the average absolute price difference across IFA for 2011-12 was $€ 11 / \mathrm{MWh} .{ }^{14}$ Using data from ACER (2015, fig 63) absolute average price differences across four important price zones (EEX, Nordpool, OMIE, EPEX, GME) weighted by interconnector flows have shown some convergence, from $€ 11.66 / \mathrm{MWh}$ in 2008 to $€ 11.79 / \mathrm{MWh}$ in 2012 and then falling to $€ 6.83$ in 2014. This last figure is consistent with congestion revenue for 2014 (ACER, 2015, fig 75) which, assuming 8,000 hrs full utilization and efficient coupling for all of the $48 \mathrm{GW}$ interconnector reported, implies $€ 5.8 / \mathrm{MWh}$. The actual price difference will be higher than this as they were not all efficiently coupled.

\footnotetext{
${ }^{14}$ Newbery et al $(2013$, tables $8.2,8.4)$ assuming an average of $1,250 \mathrm{MW}$ for 8,760 hours.
} 
Additional estimates come from the incremental value of expanding interconnectors, which ACER (2015, fig 84) provides for a sample of 24 such links. The values are given in $€$ million per $100 \mathrm{MW}$ extra capacity, assuming no change in prices at each end. This allows an estimate of the average initial price difference across each, assuming $100 \%$ utilization of the extra $100 \mathrm{MW}$ for $8,000 \mathrm{hrs} / \mathrm{yr}$. The 5-year average between 2011-14 was €6/MWh (varying from €5-7) with a standard deviation across all 24 interconnectors of $€ 6 / \mathrm{MWh}$. Again price convergence implies a higher pre-coupling value.

As noted above, prices have been converging over time and the proportion of flows in the wrong direction and the underutilization of interconnectors have both been falling (ACER, 2014, figs 85-6). Thus at the 2012 value of $€ 11.79 / \mathrm{MWh}$ of the preintegration price difference (arguably an underestimate) the average value of the gains from trade of $315 \mathrm{TWh}$ would have been $€ 3.7$ billion/yr, compared to the value of total wholesale demand of $€ 150$ billion at an average wholesale price of $€ 50 / \mathrm{MWh}^{15}$ If the estimated $10-20 \%$ welfare loss as a percentage of the gains from trade were to hold across the whole EU, the gains from efficient market coupling compared to the 2004 case of no coupling would be $€ 370-740$ million per year, or $0.25-0.5 \%$ of wholesale market value.

ACER $(2014,2015)$ adopted the simpler form of our methodology, ignoring price changes and calculating the initial price difference times the change in volume as presented in Table 1, which gives the 2014 gains as a percent of the trade value assuming

\footnotetext{
15 That was the estimate for 2011 and equal to the measured price in 2012, which fell slightly to $€ 46 / \mathrm{MWh}$ in 2013, see ACER (2014b, fig 35).
} 
the average price difference of $€ 6.83 / \mathrm{MWh}$ above. Some of the individual values in the originally published ACER Report were implausibly high, particularly those between the Single Electricity Market (SEM, the combined markets of NI and IE) and GB. After discussions with ACER, these figures were revised in the version placed on the website in December 2014 (and the 2015 data repeat the correct 2013 values). They are still high in relation to capacity, even though they have been minimized by putting the links in at their full nominal value, although the NI-GB link has been at only $50 \%$ capacity for some time. A quick calculation for 2012 for NI-GB in Appendix Table A2 suggests a loss of $€ 7.5$ million in 2012 , which is very different from the original value of $€ 43.6 \mathrm{~m}$ and even the revised value of $€ 21.82 \mathrm{~m}$ shown in Table 1. SEM Committee (2011) estimated the 2010 welfare loss of both SEM-GB cables together at $€ 30$ million. Table 1 therefore shows the subtotals ignoring the two SEM-GB interconnectors, and including them (the bottom line). In what follows the figures exclude the SEM, which, if included, is given in brackets. Thus the total loss in Table 1 for 2012 is $€ 298 \mathrm{~m} / \mathrm{yr}, 14 \%$ of trade value (€320m/yr, 15\%), falling to $€ 129(€ 199) \mathrm{m} / \mathrm{yr}$ in $2014,11 \%(16 \%)$ of the lower trade value (most interconnectors were coupled by mid-year). That is towards the lower of the estimate given above, which is understandable given price convergence and progress with coupling.

\section{Table 1}

Columns 2-4 in Table 1 give the ACER data. Column 5 gives the average contribution of each interconnector to the total measured loss as a percentage. Column 6 gives the Net Transfer Capacity (NTC) based on the 2012 data used by Newbery et al. (2013), updated for some interconnectors from web searches. These figures should be 
treated as rough estimates, since the variation on some interconnectors is from zero to several times the value shown in the table, and the weighted average standard deviation (SD) of the hourly 2012 NTCs on these borders was $42 \%$.

Table 1 shows the loss per MW of interconnector capacity of $€ 13,560 / \mathrm{MWyr}$. Scaling this up by the lower of import and export capacity of 83 GW gives $€ 1,125$ million/yr, although by 2014 the loss had fallen to $€ 5,860 / \mathrm{MWyr}$, scaling to a reduced level of losses of $€ 490$ million/yr after (substantially) more coupling. The final two columns takes the estimated loss and divides it by the value of potential arbitrage trade for 8,000 hours per year at $100 \%$ utilization and assuming an arbitrage gain of $€ 11.79 / \mathrm{MWh}(€ 6.83 / \mathrm{MWh}$ in 2014$)$, and this welfare loss as a proportion of the potential arbitrage gains from trade is $14 \%$ in 2012 , right in the middle of the range estimated above from the small sample of four interconnectors. One caveat noted above is that if all interconnectors are efficiently coupled, then the gains over each interconnector may fall, so scaling up to the whole of the EU may overestimate the total gains. The IFA example suggested that price changes might reduce the gains by $10 \%$, in which case the EU-wide gains from coupling might fall to $€ 1,010 \mathrm{~m} / \mathrm{yr}$ or 0.7 of $1 \%$ of total EU wholesale market value.

\subsection{Other gains from improved market integration}

The Target Electricity Model aims to integrate markets not just at the day-ahead stage, but intra-day and real-time via sharing balancing services, as well as sharing reserve capacity and allowing more efficient cross-border trading up to three years before delivery. As at end-2015, day-ahead coupling is largely complete, but other market 
integration is lagging. DG ENER commissioned the authors to look ahead to 2020 and 2030 to estimate the potential for future gains from more complete integration, for which Newbery et al $(2013, \S 5.3)$ constructed various scenarios. The model is set out in detail in Pudjianto et al. (2014). The Baseline scenario considered the persistence of 2014 institutions (i.e. the TEM) but with continued self-reliance on security of supply, so that each country would invest in enough capacity to meet its reliability standard without importing in stress periods. It would choose that capacity to meet its renewables targets and build the EU planned transmission - 4 TWkm by 2015 and 45 TWkm by 2030 from the report's base data date of around 2012.. ${ }^{16}$ The Integrated scenario goes further in sharing reserves, but not balancing services. In case it is not possible to build all the planned transmission, the Int Low-TX case only builds half the justified transmission links. The Int Self-secure assumes countries continue to have adequate capacity to meet reliability standards without imports but is otherwise the same as Integrated. Int EU Reserve extends Integrated to include full cross-border balancing. Finally Int DSR also includes full demand side response with smart grids to manage peaks more economically. Figure 2 presents the results for Continuing Policy (CP) in terms of current renewables targets.

Fig. 2

\footnotetext{
${ }^{16}$ ENTSO-E publishes Ten Year Network Development Plans every two years and the latest (2014) at https://www.entsoe.eu/major-projects/ten-year-network-development-plan/tyndp2014/Pages/default.aspx lists 48,000 km of new or upgraded lines over the next decade, with an average size above 1 GW (TYNDP 2014, pp71-3)
} 
For present purposes it is the difference between scenarios that is more relevant for market integration, as the main gains in absolute terms come from building socially beneficial interconnection, whose value rises sharply with increased renewables penetration. Thus Integrated 2020 estimated the additional gains that could come from efficiently moving away a case of national self-security and sharing reserves while completing the ambitious transmission investment but only using these for short-term arbitrage of the kind discussed above. In the less optimistic case in which only half the planned transmission investment is completed the impact is quite modest by 2020 (Int Low TX vs Integrated) reducing benefits by $€ 1.3-1.8 \mathrm{bn} / \mathrm{yr}$. The benefit of sharing reserves (Int self-secure vs Integrated) is $€ 1.5-3.6 \mathrm{bn} / \mathrm{yr}$, and the additional benefit of also sharing balancing services (Int EU reserve vs Integrated) is only $€ 0.1 \mathrm{bn} / \mathrm{yr}$ by 2020 . In contrast adding DSR and smart grids to better manage peaks across borders (Int DSR vs Int EU reserve) adds a further $€ 1.6-2.8 \mathrm{bn} / \mathrm{yr}$ by 2020 . Such gains would take substantial investment and considerable institutional change, as well as trust, to deliver, which will take time - the TEM has already taken nearly two decades since the initial steps with the first Electricity Directive 96/92/EC. In the shorter run it is worth estimating the more realizable gains from better intra-day trading and balancing, addressed in ACER (2014).

\subsection{Intra-day trading benefits}

Since 2010 , day-ahead utilization of interconnectors has risen from $32.1 \%$ to $40.0 \%$ in 2014 or by $25 \%$, while intra-day commercial (i.e. not TSO led) trading on borders with 27 GW NTC increased from $1.8 \%$ to $4.1 \%$ of NTC between $2010-14$, or by $130 \%$ (ACER 2015, fig 92). 
Data provided in ACER (2014) give some indication of the potential gains from better intra-day integration, and are reproduced as Appendix Table A3. Table A3 shows the benefits from more efficient intra-day trading over the borders sampled were $€ 22,300 / \mathrm{MWyr}$ of interconnector capacity, or, dividing by $8,760 \mathrm{hrs} / \mathrm{yr}, € 2.55 / \mathrm{MWh}$ (SD $=€ 0.6$, from the last two columns of Table A3). If interconnectors are only $40 \%$ fully utilized (ACER, 2014, fig 50) and if the total interconnector capacity is $83 \mathrm{GW},{ }^{17}$ and if the volume of intra-day trading might double from its 2012 low level of $3 \%$, an extra 2,400 MW might be available on average perhaps 6,000 hours per year ${ }^{18}$ with a total value of $€ 37$ million/yr. This is consistent with scaling up the data in table A3 to the total interconnector capacity level, and assuming $200 \mathrm{MW}$ are traded on the days when significant price differences are observed, ${ }^{19}$ also giving a value of $€ 37$ million/yr.

\subsection{Balancing service benefits}

DG ENER commissioned Mott MacDonald (2013) to estimate the potential gains from integrating European balancing markets for ACER's Impact Assessment of the Electricity Balancing Framework Guidelines. The report estimated balancing benefits between GB and France of about $€ 50$ million/yr, and for the Nordic countries of about $€ 220$ million/yr

\footnotetext{
${ }^{17}$ Data in convenient matrix form is available at https://www.entsoe.eu/fileadmin/user upload/ library/ntc/archive/NTC-Values-Winter-20102011.pdf but post 2011 data does not seem to be available in convenient matrix form. The totals are the lower of import or export values limited by maxima.

${ }^{18}$ NTCs vary by season and for other reasons so this is a guesstimate of availability of $68 \%$.

${ }^{19}$ The hours recorded in Table A3 assume at least $100 \mathrm{MW}$ were free, so the assumption here is that as that was a de minimis cut-off, the actual is twice as high.
} 
compared to individual "stand alone" balancing. Looking ahead to 2030 under "hypothetical" scenarios of the future European Power System, the estimated benefits increase with wind penetration and justify investing to enhance interconnectivity. Assuming the extra interconnection is built, integrating balancing markets and sharing reserves could achieve operational cost savings of about $€ 3 \mathrm{bn} / \mathrm{year}$ and reduce (by up to $40 \%$ ) the required reserve capacity.

ACER (2014) provides estimates of the potential gains transcribed in Table 2 for a selection of borders in 2013 .

\section{Table 2}

The simplest benefit to be gained is the netting of imbalances, in which one side of the border is short and the other side long, so that together they can reduce imbalances on each side. The other obvious benefit is to be derived from procuring balancing energy from abroad when it is cheaper. Table 2 gives estimates of each. The total value for FRGB is $€ 39 \mathrm{~m} / \mathrm{yr}$, which can be compared with the estimates given in Mott MacDonald (2013) of full unconstrained Common Merit Order shared balancing between France and GB of $€ 50 \mathrm{~m} / \mathrm{yr}$, which is of comparable size, given the difficulties of properly modeling the potential benefits. If one takes the balancing benefit as $€ 33,000 / \mathrm{MWyr}$ (from the bottom right average) and if that is scaled up to the 2 GW FR-GB interconnector, the result would be $€ 66 \mathrm{~m}$, rather higher than this estimate, but again comparable.

If this balancing benefit of $€ 33,000 / \mathrm{MWyr}$ is scaled up to the $83 \mathrm{GW}$ of interconnection, the result would be $€ 2.7 \mathrm{bn} / \mathrm{yr}$, which seems high. Figure 2 gives a model-based estimate of shared balancing for 2015 (Int EU reserves less Int self-secure) varying from $€ 1.2-2.8 \mathrm{bn} / \mathrm{yr}$ and from $€ 1.6-3.7 \mathrm{bn} / \mathrm{yr}$ by 2020 , when higher 
intermittency would increase the value of shared balancing. These estimates, however, were additional to all the other benefits of market integration, and clearly if intra-day trading is both efficient and continued until just before dispatch, the remaining benefits from subsequent balancing will have already been largely captured. In short, there are problems in allocating the gains from integration over different time-scales, particularly as forecasting improves, and so one should not attach particular weight to one part of the total gains. There is the additional point that by its nature it is difficult to properly model future imbalances in an optimizing engineering model, as these rely on imperfections that the model may be designed to ignore, as well as estimating the scarcity costs given the many short-run constraints limited their delivery.

ACER (2014, p140) admits that it is very difficult to properly value the potential benefits of sharing balancing services as that could "be obtained only through having access to (and the ability to process) all the data corresponding to the bids and offers submitted by all BSPs from all the imbalance areas". Instead the estimate is based on "the imbalance price differences across imbalance price areas in Europe." Using the data from ACER (2014, fig 56) shown in Table 2 one can calculate the value of netting and exchanging energy in $€ / \mathrm{MWh}$ (the penultimate last two columns) which show netting values of $€ 32 / \mathrm{MWh}$ and $€ 27 / \mathrm{MWh}$ respectively, substantially higher than the day-ahead arbitrage values, but not implausible for balancing markets.

Given the very high total value based on a simple extrapolation from the data in Table 2, it is worth exploring how better to extrapolate to the EU-28 from data covering only one-fifth of cross-border interconnection. From the data in table 2, the coefficients of variation $(\mathrm{CVs})$ of netting and energy trading per $\mathrm{MWh}$ are $72 \%$ and $134 \%$ and the $\mathrm{CV}$ 
of the total benefits per MW is $146 \%$, while the average of the two least valuable borders is one third the average value. If the remaining interconnectors are one-third as valuable per MW NTC, given that the potential benefits identified in the subset of interconnectors amounts to $€ 575$ million, (larger for this subset than all the other potential gains), the total would be $€ 1.3$ billion per year, or $41 \%$ of the total estimated gains from trade (and double the upper end of the estimated arbitrage gains from coupling). If so, then the benefits from integrating cross-border balancing are considerably larger than those from coupling at the day-ahead stage, and if to realize these gains more spare capacity has to be held back to facilitate balancing, that would seem worthwhile.

On the other hand, sharing balancing across borders is just one way of delivering flexibility at short notice, and as dispatch becomes smarter, and as more Demand Side Resources and storage are made available, so the marginal value of any one source of flexibility is likely to fall. Offsetting that will be the growth in need for flexibility with the growth in intermittent wind and solar PV generation.

\subsection{Welfare impact of unscheduled flows}

Acer (2015, figure 72 and Table A8) distinguishes between loop flows and unscheduled transit flows, which together are classified as unscheduled flows that arise because of imperfect coordination between TSOs, and the desire to treat each dispatch zone as a copper plate, instead of the US Standard Market Design (SMD) of nodal pricing. One dramatic measure of the mismatch between an efficient dispatch achievable under the SMD and that from the excessively large price zones in the EU is given by the ratio of NTC to thermal capacity, which averaged over the 44 links studied covering $82 \mathrm{GW}$ is only 30\% (ACER, 2015, fig 67). Central dispatch using a complete grid description 
would make use of this entire thermal capacity. The cost of redispatch and the underutilization of potential capacity is a measure of what could be achieved with further reforms.

ACER has more than doubled their earlier estimates (ACER, 2015, p169) as a result of now including the impact on reliability margins. ACER only measures the inefficiency for 21 "highly impacted borders" with an average (one-direction) NTC of 35 GW out of a total of $96 \mathrm{GW}$. The cost of this inefficiency has risen from $€ 793$ million in 2011 to a peak of $€ 1,095$ million in 2013 before falling as a result of lower wholesale prices, with an average over the four years of $€ 988$ million. The average gains are thus $€ 28$ million/GW NTC, and if the remaining borders are only one quarter as valuable, the potential gains would be roughly $€ 1,360$ million/year. This is substantial and a measure of the failure to have nodal pricing (or at least far more price zones along congestion boundaries).

\subsection{Costs of curtailment at borders}

Acer (2015, fig 74) gives the costs of curtailment at a selected set of borders, a subset of which is reproduced with NTC data in Table A4. For the $26 \mathrm{GW}$ of borders for which data are available for all years 2012-14 the total cost averaged $€ 715 / \mathrm{MWyr}$, with costs rising over time (presumably as renewables increase in volume). As several borders have been curtailed in both directions one can scale up in two ways. The higher estimate would be to take the higher value direction only for those for which we have values in both directions, for which there are $6.35 \mathrm{GW}$ with data for all years, for which the average cost was $€ 1,998 / \mathrm{MWyr}$, but only include export interconnector capacity. Scaling this up to 83 GW total would give an annual cost of $€ 166$ million/yr. The lower value would be to 
scale up the overall average in the final line of $€ 715 / \mathrm{MWyr}$ by the sum of export and import capacities of $182 \mathrm{GW}$, which would give $€ 130$ million/yr.

\subsection{Summary of benefits}

The high value of increasing the efficiency of interconnector use is clear at a number of critical borders. The earlier estimate of the gains from increasing cross-border trade from $10 \%$ of demand ( $315 \mathrm{TWh}$ ) to $15 \%$ of demand (i.e. by $158 \mathrm{TWh}$ ) assumed an average price difference before and after trade of $€ 10 / \mathrm{MWh}$ and gives the benefit as $€ 1.58$ billion/yr or $1 \%$ of the value of wholesale demand. This might be an under-estimate if some fraction of trade is in a perverse direction. Just improving the existing day-ahead arbitrage trade on interconnectors through coupling is worth $10-20 \%$ of the potential gains from trade, which at $€ 12 / \mathrm{MWh}$ is $10-20 \%$ of $€ 3.8$ billion/yr or $€ 380-760$ million/yr. The estimate of $10-20 \%$ of potential trade is consistent with the day-ahead arbitrage gains estimated in Table 1, reported in summary table 3, but as they are scaled up to all interconnectors based on the gains per MW of capacity, they are then considerably larger at $€ 1$ billion/yr.

\section{Table 3}

However, in addition to these arbitrage gains from market integration, intra-day trading might be worth $€ 40$ million/yr, balancing benefits which might be $€ 1.3$ billion/yr or could be as large as $€ 2.7$ billion/yr, with proportionate scaling. These short-term realizable gains amount to $€ 2.4$ billion/yr and are itemized and subtotaled in Table 3 .

If unscheduled flows could be prevented (which might require a significant design change to nodal pricing) then an additional $€ 1$ billion might be gained. Finally, the cost of curtailment might be $€ 130-160$ million. 


\section{Conclusions and Policy Implications}

Table 3 shows that including these longer-term potential benefits with the short-term trading and balancing benefits gives total integration benefits of $€ 3.9 \mathrm{bn} / \mathrm{yr}$, which is $2.6 \%$ of the value of 2012 wholesale demand, but more than $100 \%$ of the current gains from trade over the interconnectors, a more relevant metric.

Specifically, if realizing these benefits and passing them through to interconnector owners, this increase of $100 \%$ should make already commercially attractive investments in interconnectors become even more so, and perhaps a large number of currently marginal investments would look attractive. Given that the Commission and ENTSO-E are pressing against considerable local resistance to increase interconnector capacity the most immediate policy implication is to ensure that the gains of market integration are properly allocated to their sources, and hence provide incentives for their enhancement. Certainly the case studies considered suggested that expanding transmission links that are severely congested is already likely to be very cost effective.

The conclusion is that market coupling delivers total benefits that should substantially exceed the costs of the required market design changes, and that the delays in market integration since the market integration project started in 1997 have been large. Further gains could be reaped from a move to nodal pricing but these would have to be counterbalanced against the claimed loss of liquidity and scope for market manipulation that such a move might risk. What emerges very strongly is the growing need for more interconnection and the policy implication to ensure that interconnectors are remunerated for the whole range of services they provide. 


\section{Acknowledgements}

This paper builds on and extends work under contract ENER/B1/491-1/2012, published as Newbery et al. (2013). We would like to thank Martin Godfried of ACER for providing some of the data supporting ACER (2014a), commenting on an earlier draft and correcting some of the units in which the original published ACER tables were presented, and two referees for their constructive comments, but they should not be held responsible for any remaining errors in this paper.

\section{References}

ACER, 2012. ACER/CEER Annual Report on the Results of Monitoring the Internal Electricity and Natural Gas Markets in 2011, 29 Nov. 2012, Ljubljana, at http://www.acer.europa.eu/Official documents/Publications/Documents/ACER\%20Mark et $\% 20$ Monitoring $\% 20$ Report.pdf

ACER, 2013. ACER/CEER Annual Report on the Results of Monitoring the Internal Electricity and Natural Gas Markets in 2012, Nov., Ljubljana at http://www.acer.europa.eu/Official documents/Acts of the Agency/Publication/ACER \%20Market\%20Monitoring\%20Report\%202013.pdf

ACER, 2014a. ACER/CEER Annual Report on the Results of Monitoring the Internal Electricity and Natural Gas Markets in 2013, Oct., Ljubljana at http://www.acer.europa.eu/Official documents/Acts of the Agency/Publication/ACER Market_Monitoring_Report_2014.pdf

ACER, 2014b. Public data underlying the figures of Annual Report on the Results of Monitoring the Internal Electricity and Natural Gas Markets in 2013, at http://www.acer.europa.eu/Events/Launch-of-the-ACERCEER-Monitoring-report-onthe-internal-electricity-and-gas-markets- 
/Documents/Public\%20data\%20underlying\%20the \%20figures $\% 20$ published $\% 20$ on $\% 20$

ACER\%20CEER\%20Annual\%20Market\%20Monitoring\%20Report\%202013.pdf, this

version accessed 16 Dec 2014)

ACER, 2015. ACER/CEER Annual Report on the Results of Monitoring the Internal Electricity and Natural Gas Markets in 2014, Oct., Ljubljana at

http://www.acer.europa.eu/Official_documents/Acts_of the Agency/Publication/ACER Market_Monitoring Report 2015.pdf

Böckers, V., Haucap, J., \& Heimeshoff, U., 2013. Benefits of an integrated European electricity market: the role of competition, Annex IV to Cost of Non-Europe in the Single Market for Energy, report requested by the General Secretariat of the European Parliament, at http://www.europarl.europa.eu/RegData/etudes/etudes/join/2013/504466/IPOLJOIN ET\%282013\%29504466\%28ANN04\%29 EN.pdf

De Jong, H, Hakvoort, R., \& Sharma, M., 2007. Effects of Flow-based Market Coupling for the CWE region, 1-9, Proceedings of the 4th European Congress Economics and Management of Energy in Industry, ECEMEI2007).

EC, 2013. Commission Regulation (EU) No 543/2013 on submission and publication of data in electricity markets and amending Annex I to Regulation (EC) No 714/2009 of the European Parliament and of the Council, at http://eur-lex.europa.eu/legalcontent/EN/TXT/?uri=CELEX:32013R0543

DECC, 2014. EMR Panel of Technical Experts' Final Report on National Grid's Electricity Capacity Report, at https://www.gov.uk/government/uploads/system/uploads/attachment_data/file/252743/Ca pacity_Market_Impact_Assessment_Oct_2013.pdf

Leuthold, F., Rumiantseva, I., Weigt, H., Jeske, T. \& Hirschhausen, C. von, 2005. Nodal Pricing in the German Electricity Sector - A Welfare Economics Analysis, with Particular Reference to Implementing Offshore Wind Capacities, Working Paper WP-EM-08a, 
Dresden University of Technology, Chair for Energy Economics and Public Sector Management.

Mansur, E. T. \& White, M. W., 2009. Market organization and efficiency in electricity markets, (2012 revised version) at $\underline{\text { http://www.dartmouth.edu/ mansur/papers/mansur_white pjmaep.pdf }}$

Meeus, L., 2011. Implicit auctioning on the Kontek Cable: third time lucky? Energy Econ. 33(3), $413-418$

Mott MacDonald, 2013. Impact Assessment on European Electricity Balancing Market, March, report EC DG ENER/B2/524/2011 at http://ec.europa.eu/energy/gas electricity/studies/doc/electricity/20130610 eu balancing master.pdf.

NAO, 2003. The New Electricity Trading Arrangements in England and Wales, at http://www.nao.org.uk/report/the-new-electricity-trading-arrangements-in-england-and$\underline{\text { wales/ }}$

National Grid, 2014. Electricity Capacity Report, at http://www2.nationalgrid.com/UK/Our\%20company/Electricity/Market\%20Reform/Ann ouncements/June\%202014\%20Auction\%20Guidelines\%20publication/

National Grid, 2015. Electricity Capacity Report, at https://www.emrdeliverybody.com/Capacity\%20Markets\%20Document\%20Library/Elec tricity\%20Capacity\%20Report\%202015.pdf

Neuhoff, K., Barquin, J., Boots, M.G., Ehrenmann, A., Hobbs, B.F., Rijkers, F.A., Vazquez, M., 2005. Network-constrained Cournot models of liberalized electricity markets: the devil is in the details. Energy Economics 27, 495-525. doi: http://dx.doi.org/10.1016/j.eneco.2004.12.001 .

Neuhoff, K., Boyd, R., Grau, T., Barquin, J., Echabarren, F., Bialek, J., Dent, C., von Hirschhausen, C., Hobbs, B. F., Kunz, F. , Weigt, H., Nabe, C., Papaefthymiou, G., \& 
Weber, C., 2011. Renewable Electric Energy Integration: Quantifying the Value of Design of Markets for International Transmission Capacity, DIW Berlin Discussion Papers 1166.

Newbery, D.M., Strbac, G., Pudjianto, D., Noël, P., Booz \& Co. \& LeighFisher, 2013. Benefits of an Integrated European Energy Market: Final report for DG ENER, July at http://ec.europa.eu/energy/infrastructure/studies/doc/20130902_energy_integration_benef its.pdf

Newbery, D.M. \& Grubb, M., 2015. Security of Supply, the Role of Interconnectors and Option Values: insights from the GB Capacity Auction, Econ. Energy \& Environmental Policy, 4(2), 65- 81. doi http://dx.doi.org/10.5547/2160-5890.4.2.dnew

Newbery, D.M. 2016. Towards a green energy economy? The EU Energy Union's transition to a low-carbon zero subsidy electricity system - lessons from the UK's Electricity Market Reform, Applied Energy, in press. Doi: http://dx.doi.org/10.1016/j.apenergy.2016.01.046 Ott, A., 2010. PJM - LMP Market Overview, Presented at CPI/Re-shaping workshop in Brussels. PCR, 2016. EUPHEMIA Public Description: PCR Market Coupling Algorithm, Version 1.3 at https://www.epexspot.com/document/34460/Euphemia\%3A\%20Public\%20documentatio $\underline{\mathrm{n} \% 20-\% 20 \text { January } \% 202016}$

Pellini, E., 2014. Essays on European Electricity Market Integration, submitted for the degree of Doctor of Philosophy in Energy Economics, Surrey, at http://www.seec.surrey.ac.uk/PGProgs/PhDTheses/2014ElisabettaPelliniThesis.pdf

Pudjianto D, Aunedi M, Djapic P, Strbac G, 2014. Whole-Systems Assessment of the Value of Energy Storage in Low-Carbon Electricity Systems, IEEE Transaction on Smart Grid, 5, 1098-1109.

SEM Committee, 2011. Proposed Costs and Estimation of Benefits of the Introduction of additional Intra Day Gate Closures in the SEM - Information Paper, SEM -11-023, 21 Apr. at http://www.allislandproject.org/en/sem publications.aspx?year=2011 


\section{Appendix}

Using the same methods set out in Newbery et al (2013) it is straightforward to compute the social welfare losses on the Spanish-French interconnection for 2011 and 2012, ignoring resistive losses as this is a short $\mathrm{AC}$ interconnection, and similarly for the Moyle interconnector between GB and NI.

\section{Table A1}

\section{Table A2}

Table A4 takes the raw data from ACER (2015) and rearranges the borders into the directions with the larger of the two flows on that border in the top part, then the smaller valued direction, then the borders with only one direction recorded, first for which both years' data are available, then for those with data in only one year, and finally totals and averages for each year and for both years. The values are then related to the estimated NTC values for 2011 from the ETSO NTC matrix.

\section{Table A3}

\section{Table A4}




\section{Figures and tables}
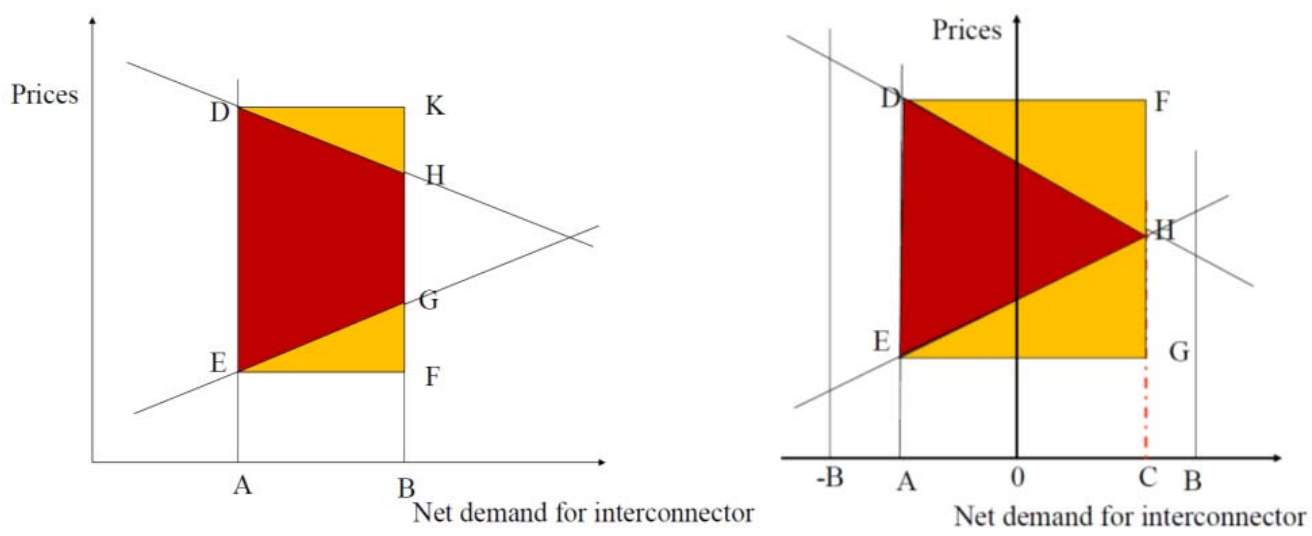

Fig. 1 Benefits of market coupling: a) assuming no adverse flows and b) with flow originally against price differential

Table 1

Estimated 'loss in social welfare' 2012-2014

\begin{tabular}{|c|c|c|c|c|c|c|c|c|}
\hline Border & $\begin{array}{c}2012 \\
€ \text { million }\end{array}$ & $\begin{array}{c}2013 \\
€ \\
\text { million }\end{array}$ & $\begin{array}{c}2014 \\
€ \\
\text { million }\end{array}$ & $\begin{array}{c}\text { average } \\
\text { share }\end{array}$ & $\begin{array}{l}2012 \\
\text { NTC } \\
\text { MW }\end{array}$ & $\begin{array}{l}2012 \text { Loss } \\
\text { €'000/MWyr }\end{array}$ & loss & from \\
\hline $\mathrm{CH}-\mathrm{FR}$ & $€ 66.36$ & $€ 68.81$ & $€ 39.60$ & $20 \%$ & 2,300 & $€ 28.85$ & $31 \%$ & $32 \%$ \\
\hline CH-DE & $€ 39.25$ & $€ 41.81$ & $€ 29.70$ & $13 \%$ & 4,000 & $€ 9.81$ & $10 \%$ & $14 \%$ \\
\hline $\mathrm{CH}-\mathrm{IT}$ & $€ 33.45$ & $€ 17.64$ & $€ 5.70$ & $7 \%$ & 4,000 & $€ 8.36$ & $9 \%$ & $3 \%$ \\
\hline CZ-DE & $€ 32.98$ & $€ 35.13$ & n.a. & $12 \%$ & 1,600 & $€ 20.61$ & $22 \%$ & \\
\hline AT-CZ & $€ 23.28$ & $€ 16.21$ & $€ 12.10$ & $6 \%$ & 800 & $€ 29.10$ & $31 \%$ & $28 \%$ \\
\hline FR-IT & $€ 18.85$ & $€ 18.13$ & $€ 5.40$ & $5 \%$ & 2,700 & $€ 6.98$ & $7 \%$ & $4 \%$ \\
\hline AT-SI & $€ 18.37$ & $€ 18.73$ & $€ 8.40$ & $5 \%$ & 900 & $€ 20.41$ & $22 \%$ & $17 \%$ \\
\hline AT-HU & $€ 17.69$ & $€ 14.56$ & $€ 7.40$ & $5 \%$ & 800 & $€ 22.11$ & $23 \%$ & $17 \%$ \\
\hline FR-GB & $€ 14.03$ & $€ 15.85$ & $€ 1.90$ & $4 \%$ & 2,000 & $€ 7.02$ & $7 \%$ & $2 \%$ \\
\hline AT-CH & $€ 13.24$ & $€ 14.54$ & $€ 10.70$ & $5 \%$ & 900 & $€ 14.71$ & $16 \%$ & $22 \%$ \\
\hline NL-GB & $€ 12.53$ & $€ 10.06$ & $€ 1.30$ & $3 \%$ & 1,000 & $€ 12.53$ & $13 \%$ & $2 \%$ \\
\hline ES-FR & $€ 8.34$ & $€ 7.25$ & $€ 6.80$ & $3 \%$ & 1,000 & $€ 8.34$ & $9 \%$ & $12 \%$ \\
\hline subtotal/av & $€ 298.4$ & $€ 278.7$ & $€ 129.0$ & $83 \%$ & 22,000 & $€ 13.56$ & $14 \%$ & $11 \%$ \\
\hline IE-GB & $€ 0.32$ & $€ 33.58$ & $€ 48.80$ & $10 \%$ & 500 & $€ 0.64$ & $1 \%$ & $179 \%$ \\
\hline NI-GB & $€ 21.82$ & $€ 21.07$ & $€ 21.50$ & $8 \%$ & 500 & $€ 43.64$ & $46 \%$ & $79 \%$ \\
\hline Total/av & $€ 320.5$ & $€ 333.4$ & $€ 199.3$ & $100 \%$ & 23,000 & $€ 13.94$ & $15 \%$ & $16 \%$ \\
\hline
\end{tabular}

Source: ACER (2014b, fig 47) and ENTSO-E for estimated NTCs 


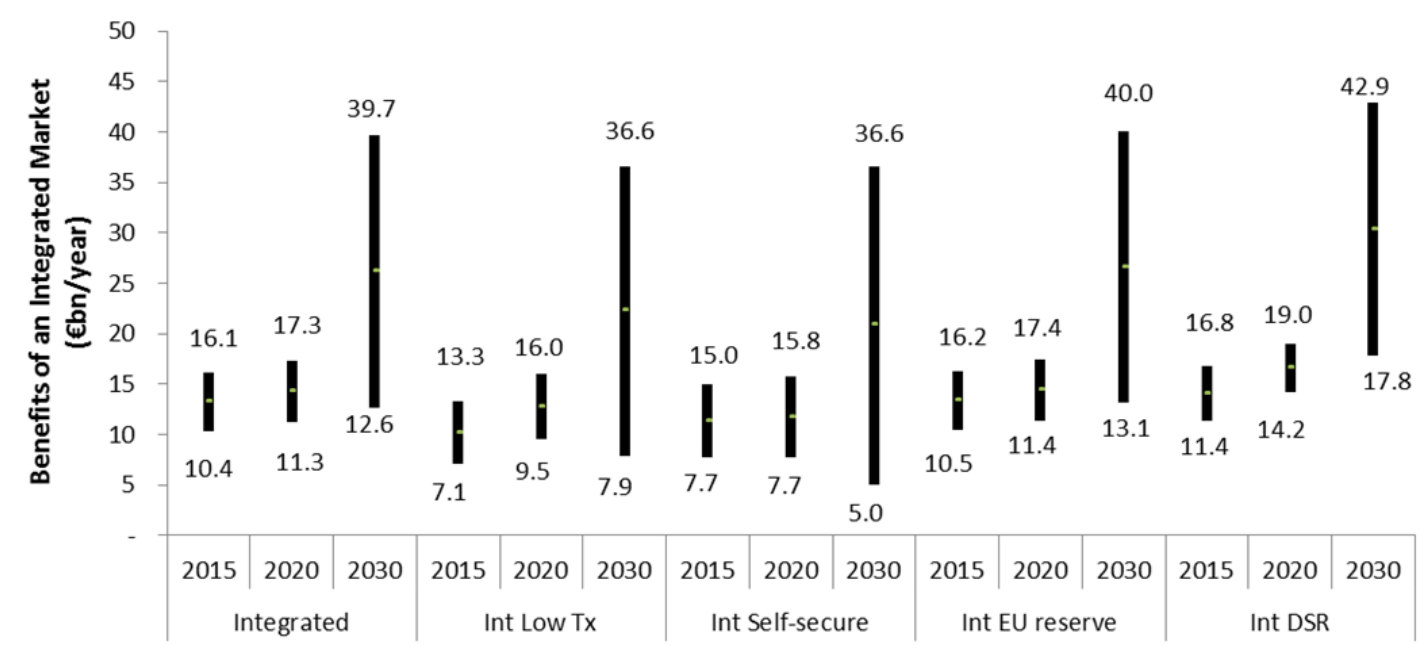

Fig. 2. Range of annual cost savings in integration scenarios relative to Baseline, $\mathrm{CP}$ market scenario, 2015-2030

Source: Newbery et al. (2013) 
Table 2

Estimate of potential benefits from the integration of balancing energy markets per border, 2013

\begin{tabular}{|c|c|c|c|c|c|c|c|c|}
\hline & $\begin{array}{l}\text { Potential } \\
\text { imbalance } \\
\text { netting } \\
\text { GWh }\end{array}$ & $\begin{array}{l}\text { Potential } \\
\text { exchange } \\
\text { balancing } \\
\text { energy GWh }\end{array}$ & $\begin{array}{l}\max \\
2012 \\
\text { NTC MW }\end{array}$ & $\begin{array}{l}\text { Netting } \\
\text { benefits } \\
€ \text { million }\end{array}$ & $\begin{array}{l}\text { Exchange } \\
\text { benefits } \\
€ \text { million }\end{array}$ & $\begin{array}{l}\text { Netting } \\
\text { value per } \\
€ / M W h\end{array}$ & $\begin{array}{l}\text { Exchange } \\
\text { value per } \\
€ / M W h\end{array}$ & $\begin{array}{l}\text { Total } \\
\text { benefit } \\
€^{\prime} 000 / \mathrm{MWyr}\end{array}$ \\
\hline GB-NL & 231.95 & $1,816.45$ & 1,000 & $€ 15.9$ & $€ 66.5$ & $€ 68.38$ & $€ 36.60$ & $€ 82.4$ \\
\hline ES-PT & 727.46 & $3,595.93$ & 2,400 & $€ 25.3$ & $€ 50.2$ & $€ 34.78$ & $€ 13.95$ & $€ 31.4$ \\
\hline AT-CZ & 144.24 & 617.98 & 500 & $€ 12.6$ & $€ 47.3$ & $€ 87.15$ & $€ 76.49$ & $€ 119.7$ \\
\hline FR-GB & 927.49 & $1,463.55$ & 2,000 & $€ 17.5$ & $€ 21.6$ & $€ 18.88$ & $€ 14.78$ & $€ 19.6$ \\
\hline AT-HU & 140.8 & 670.10 & 800 & $€ 9.6$ & $€ 29.4$ & $€ 67.83$ & $€ 43.80$ & $€ 48.6$ \\
\hline HU-RO & 268 & $1,023.94$ & 400 & $€ 18.1$ & $€ 19.3$ & $€ 67.35$ & $€ 18.80$ & $€ 93.3$ \\
\hline FR-ES & 954.05 & $1,821.72$ & 1,300 & $€ 20.2$ & $€ 14.9$ & $€ 21.16$ & $€ 8.17$ & $€ 27.0$ \\
\hline CZ-PL & 114.85 & 457.29 & 150 & $€ 9.7$ & $€ 18.6$ & $€ 84.81$ & $€ 40.59$ & $€ 188.7$ \\
\hline FR-CH & 110.05 & $1,653.60$ & 3,200 & $€ 4.1$ & $€ 24.0$ & $€ 37.35$ & $€ 14.53$ & $€ 8.8$ \\
\hline BE-NL & & 542.17 & 1,400 & & $€ 26.8$ & & $€ 49.41$ & $€ 19.1$ \\
\hline PL-SK & 66.82 & 121.93 & 550 & $€ 6.7$ & $€ 19.8$ & $€ 99.97$ & $€ 162.31$ & $€ 48.1$ \\
\hline AT-SI & & 405.61 & 900 & & $€ 24.0$ & & $€ 59.19$ & $€ 26.7$ \\
\hline CZ-SK & & 448.33 & 1,600 & & $€ 23.5$ & & $€ 52.48$ & $€ 14.7$ \\
\hline CH-AT & 94.82 & 362.33 & 800 & $€ 4.2$ & $€ 14.6$ & $€ 44.19$ & $€ 40.38$ & $€ 23.5$ \\
\hline EE-FI & 68.18 & 434.66 & 370 & $€ 2.3$ & $€ 14.3$ & $€ 34.32$ & $€ 32.92$ & $€ 45.0$ \\
\hline HU-SK & & 300.30 & 180 & & $€ 14.1$ & & $€ 46.82$ & $€ 78.1$ \\
\hline $\begin{array}{l}\text { Total or } \\
\text { average }\end{array}$ & 3,849 & 15,736 & 17,550 & $€ 146$ & $€ 429$ & $€ 37.96$ & $€ 27.25$ & $€ 32.8$ \\
\hline
\end{tabular}

Source: ACER (2014, figs 56 and 58) and ENTSO-E

Table 3

Potential gains from market integration

\begin{tabular}{|c|c|c|c|c|c|c|c|}
\hline & \multicolumn{3}{|c|}{ ACER sample 2012} & \multicolumn{2}{|c|}{ EU-28 estimate } & \multicolumn{2}{|c|}{ Newbery et al (2013) } \\
\hline & $€$ million & $\begin{array}{l}\text { NTC } \\
2012\end{array}$ & $\begin{array}{l}€^{\prime} 000 \\
\text { /MWyr or } \\
\text { MWh }\end{array}$ & $€$ million & shares & $\begin{array}{l}€^{\prime} 000 / \\
\text { MWyr or } \\
M W h\end{array}$ & $\begin{array}{l}\text { EU-28 } \\
\text { est. € m }\end{array}$ \\
\hline $\begin{array}{l}\text { increase } \\
\text { trade } 50 \%\end{array}$ & & & & & & $€ 10 / M W h$ & $€ 1,575$ \\
\hline $\begin{array}{l}\text { Day-ahead } \\
\text { coupling }\end{array}$ & $€ 300$ & 22,000 & $€ 13.6$ & $€ 1,010$ & $26 \%$ & $€ 14.6$ & $€ 1,208$ \\
\hline $\begin{array}{l}\text { Intraday } \\
\text { coupling }\end{array}$ & & 10,050 & $€ 2.6$ & $€ 37$ & $1 \%$ & & \\
\hline Balancing & $€ 575$ & 17,550 & $€ 32.8$ & $€ 1,343$ & $35 \%$ & & \\
\hline subtotal & & & & $€ 2,390$ & $62 \%$ & & \\
\hline $\begin{array}{l}\text { Unscheduled } \\
\text { flows }\end{array}$ & $€ 988$ & 34,900 & $€ 28.3$ & $€ 1,360$ & $35 \%$ & & \\
\hline curtailment & $€ 19$ & 26,075 & $€ 0.7$ & $€ 130$ & $3 \%$ & & \\
\hline Total & & & & $€ 3,880$ & $100 \%$ & & \\
\hline
\end{tabular}

Note: The values for increased trade and intra-day coupling (highlighted and italicized) are based on values per MWh, curtailment is based on import and export flows together. 


\section{Appendix Tables}

\section{Table A1}

Social welfare loss on the Spain-France interconnection

FR-ES trade data 2011

\begin{tabular}{|l|r|r|}
\hline Potential value exports FR=>ES & $€ 53,697,430$ & $68 \%$ \\
Potential value exports ES=>FR & $€ 25,517,523$ & $32 \%$ \\
Potential total value trade & $€ 79,214,953$ & $100 \%$ \\
Loss under-export FR=>ES & $€ 3,486,071$ & $4 \%$ \\
Loss under-export ES=>FR & $€ 3,331,524$ & $4 \%$ \\
FAPD FR=>ES & $€ 1,265,000$ & $2 \%$ \\
FAPD ES=>FR & $€ 260,053$ & $0 \%$ \\
\hline Total loss & $€ 8,342,650$ & $11 \%$ \\
\hline
\end{tabular}

FR-ES trade data 2012

\begin{tabular}{|l|r|r|}
\hline Potential value exports FR=>ES & $€ 56,482,617$ & $55 \%$ \\
Potential value exports ES=>FR & $€ 45,810,192$ & $45 \%$ \\
Potential total value trade & $€ 102,292,810$ & $100 \%$ \\
Loss under-export FR=>ES & $€ 5,648,860$ & $6 \%$ \\
Loss under-export ES=>FR & $€ 3,621,960$ & $4 \%$ \\
FAPD FR=>ES & $€ 986,480$ & $1 \%$ \\
FAPD ES=>FR & $€ 1,538,622$ & $2 \%$ \\
\hline Total loss & $€ 11,795,923$ & $12 \%$ \\
\hline
\end{tabular}

\section{Table A2}

Social welfare loss on the Northern Ireland - GB Moyle interconnector 2012

\begin{tabular}{|l|rr|}
\hline Potential value of trade & $€ 44,285,421$ & $100 \%$ \\
Value of actual imports & $€ 36,814,378$ & $83 \%$ \\
Value of actual exports & $€ 9,418$ & $0 \%$ \\
total value of trade & $€ 36,823,797$ & $83 \%$ \\
Losses under-importing & $€ 3,001,142$ & $7 \%$ \\
Losses under-exporting & $€ 219,209$ & $0 \%$ \\
Losses FAPD & $€ 4,244,833$ & $10 \%$ \\
Total losses & $€ 7,465,185$ & $17 \%$ \\
\hline
\end{tabular}




\section{Table A3}

Potential for intra-day cross-border trade and efficiency in the use of cross-border intra-day capacity on a selection of EU borders - 2013 (number of hours)

\begin{tabular}{|c|c|c|c|c|c|c|c|c|c|c|}
\hline $\begin{array}{c}\text { Border and } \\
\text { auction }\end{array}$ & Direction & $\begin{array}{l}\text { Max } \\
\text { NTC } \\
2012 \\
\text { MW }\end{array}$ & 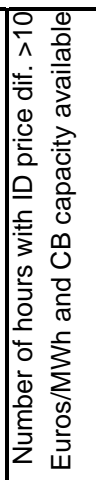 & 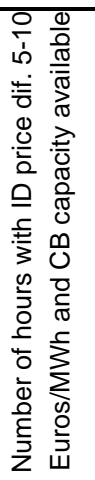 & 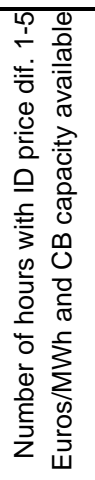 & 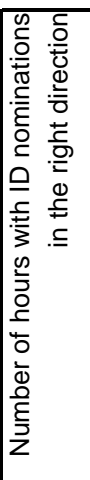 & 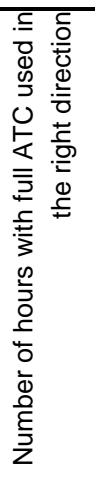 & 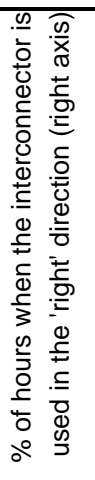 & 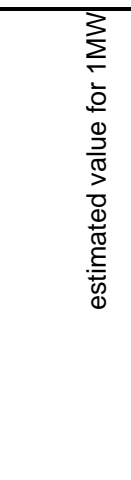 & 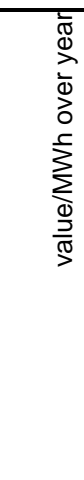 \\
\hline \multirow[t]{2}{*}{ ES-PT (implicit) } & ES->PT & 2,400 & 81 & 74 & 237 & 392 & 392 & $100 \%$ & $€ 2,444$ & \\
\hline & PT->ES & 2,300 & 67 & 86 & 225 & 378 & 378 & $100 \%$ & $€ 2,282$ & $€ 0.54$ \\
\hline \multirow[t]{2}{*}{ FR-DE (implicit cts) } & FR->DE & 1,500 & 976 & 168 & 32 & 813 & 13 & $69 \%$ & $€ 15,912$ & \\
\hline & DE->FR & 1,200 & 878 & 153 & 58 & 693 & 30 & $64 \%$ & $€ 14,415$ & $€ 3.46$ \\
\hline \multirow[t]{2}{*}{ ES-FR (explicit) } & ES->FR & 900 & 784 & 535 & 364 & 922 & 288 & $55 \%$ & $€ 16,597$ & \\
\hline & FR->ES & 1,100 & 616 & 397 & 282 & 651 & 301 & $50 \%$ & $€ 12,865$ & $€ 3.36$ \\
\hline \multirow[t]{2}{*}{ FR-BE (pro rata) } & BE->FR & 2,000 & 463 & 780 & 700 & 509 & 5 & $41 \%$ & $€ 14,505$ & \\
\hline & $\mathrm{FR}->\mathrm{BE}$ & 1,200 & 467 & 399 & 542 & 693 & 108 & $49 \%$ & $€ 11,424$ & $€ 2.96$ \\
\hline \multirow[t]{2}{*}{ FR-IT (explicit) } & FR->IT & 2,500 & 447 & 372 & 614 & 567 & 82 & $40 \%$ & $€ 11,151$ & \\
\hline & IT->FR & 1,000 & 254 & 426 & 306 & 370 & - & $38 \%$ & $€ 7,710$ & $€ 2.15$ \\
\hline \multirow[t]{2}{*}{ FR-GB (explicit) } & GB->FR & 2,000 & 431 & 321 & 423 & 435 & 24 & $37 \%$ & $€ 9,981$ & \\
\hline & FR->GB & 2,000 & 419 & 452 & 1,680 & 829 & 44 & $32 \%$ & $€ 14,489$ & $€ 2.79$ \\
\hline & $\begin{array}{c}\text { Total } \\
\text { Average per } \\
\text { interconnector }\end{array}$ & 10,050 & 981 & 694 & 911 & 1209 & 303 & $56 \%$ & $€ 22,296$ & $€ 2.55$ \\
\hline
\end{tabular}

Sources: ACER (2014 fig 53), ENTSO-E 
Table A4

Total curtailment costs per border

\begin{tabular}{|c|c|c|c|c|c|}
\hline border & 2012 & 2013 & 2014 & NTC & average/MW \\
\hline GR->IT & $€ 659,035$ & $€ 2,418,188$ & $€ 2,418,188$ & 500 & $€ 3,663.6$ \\
\hline$B G->G R$ & $€ 2,400$ & $€ 24,068$ & $€ 44,364$ & 550 & $€ 42.9$ \\
\hline AT->IT & $€ 57,179$ & $€ 328,270$ & $€ 2,730,571$ & 220 & $€ 4,721.2$ \\
\hline $\mathrm{DE}->\mathrm{CH}$ & $€ 35,115$ & $€ 12,643$ & $€ 0$ & 1,500 & $€ 10.6$ \\
\hline FR->UK & $€ 9,239,274$ & $€ 8,942,479$ & $€ 9,085,220$ & 2,000 & $€ 4,544.5$ \\
\hline$E S->F R$ & $€ 328,482$ & $€ 211,612$ & $€ 102,454$ & 580 & $€ 369.3$ \\
\hline NL->UK & $€ 88,026$ & $€ 139,902$ & $€ 1,198,157$ & 1,000 & $€ 475.4$ \\
\hline major pair & $€ 10,409,511$ & $€ 12,077,162$ & $€ 15,578,954$ & 6,350 & $€ 1,998.2$ \\
\hline IT->AT & $€ 589$ & $€ 301$ & $€ 1,941$ & 285 & $€ 3.3$ \\
\hline $\mathrm{CH}->\mathrm{DE}$ & $€ 8,205$ & $€ 2,681$ & $€ 0$ & 3,500 & $€ 1.0$ \\
\hline IT->GR & $€ 33,825$ & $€ 111,359$ & $€ 111,359$ & 500 & $€ 171.0$ \\
\hline UK->FR & $€ 3,326,577$ & $€ 807,553$ & $€ 51,332$ & 2,000 & $€ 697.6$ \\
\hline FR->ES & $€ 114,263$ & $€ 69,357$ & $€ 118,950$ & 1,300 & $€ 77.6$ \\
\hline UK->NL & $€ 271$ & $€ 197,946$ & $€ 17,128$ & 1,000 & $€ 71.8$ \\
\hline minor pair & $€ 3,483,730$ & $€ 1,189,197$ & $€ 300,710$ & 8,585 & $€ 193.1$ \\
\hline all pairs & $€ 13,893,241$ & $€ 13,266,359$ & $€ 15,879,664$ & 14,935 & $€ 960.6$ \\
\hline FR->IT & $€ 19,816$ & $€ 3,022,625$ & $€ 1,197,653$ & 2,575 & $€ 548.9$ \\
\hline $\mathrm{FR}->\mathrm{CH}$ & $€ 146,186$ & $€ 82,229$ & $€ 53,363$ & 3,200 & $€ 29.4$ \\
\hline $\mathrm{CH}->\mathrm{AT}$ & $€ 2,081$ & $€ 783$ & $€ 0$ & 1,200 & $€ 0.8$ \\
\hline $\mathrm{CH}->\mathrm{IT}$ & $€ 2,660,783$ & $€ 1,832,740$ & $€ 3,909,650$ & 4,165 & $€ 672.5$ \\
\hline subtotal & $€ 2,828,866$ & $€ 4,938,377$ & $€ 5,160,666$ & 11,140 & $€ 386.8$ \\
\hline Total & $€ 16,722,107$ & $€ 18,204,736$ & $€ 21,040,330$ & 26,075 & $€ 715.5$ \\
\hline
\end{tabular}

Sources: ACER (2015 fig 74), ENTSO-E 